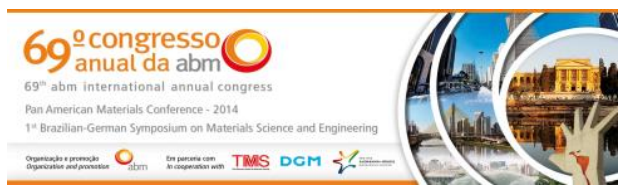

Tema: Materiais com efeito de memória de forma

\title{
AVALIAÇÃO DAS PROPRIEDADES TERMOMECÂNICAS DE FIOS SUPERELÁSTICOS DE NITINOL MICROSOLDADOS PELO PROCESSO TIG*
}

\section{Resumo}

O processo de micro soldagem se mostra eficiente para a união de Ligas com Memória de Forma (LMF) do sistema NiTi devido a alta precisão e localização do calor, diminuindo os tamanhos da zona fundida (ZF) e da zona termicamente afetada (ZTA), promovendo melhorias nas propriedades mecânicas destes tipos de juntas. Este estudo teve como objetivo geral determinar as variações das propriedades termomecânicas em juntas soldadas de fios de NiTi. Para o trabalho, fios superelásticos de uma LMF NiTi (ASTM F2063) com 0,9 mm de diâmetro, foram divididos em dois grupos: (a) fios sem tratamento térmico (NiTiA) e (b) fios com tratamento térmico a $400^{\circ} \mathrm{C}$ durante 20 minutos (NiTi400). Em seguida estes fios foram soldados pelo processo TIG, utilizando a microsoldadora Micromelt (EDG Equipamentos e Controles). A caracterização termomecânica dos fios íntegros e microsoldados foi realizada utilizando ensaios de calorimetria diferencial de varredura (DSC), análise dinâmico-mecânica (DMA), ensaios de tração uniaxial, microscopia óptica (MO), microscopia eletrônica de varredura (MEV) e microindentação Vickers. Os resultados mostraram a eficiência do processo TIG ao soldar os fios NiTi de ambos os grupos. As juntas soldadas apresentaram propriedades de superelasticidade semelhante aos fios íntegros e a análise da fratura dos fios com solda mostra características dúcteis.

Palavras-chave: Ligas com memória de forma; NiTiNOL; Microsoldagem; TIG; Superelasticidade.

\section{EVALUATION OF THE THERMOMECHANICAL BEHAVIOR OF SUPERELASTIC NITINOL WIRES MICRO WELDED BY TIG ARC PULSES}

\section{Abstract}

Micro welding is an efficient way for joining shape memory alloys (SMA) due to high accuracy and location of heat, reducing the size of the molten zone and heat affected zone (HAZ) promoting improvements in mechanical properties in these types of joints. This study aimed to determinate variations in thermomechanical properties of welded joints of $\mathrm{NiTi}$ wires. In this work, superelastic NiTi wire (ASTM F2063) $0.9 \mathrm{~mm}$ diameter were divided into two groups: (a) as received wires (NiTiA) and (b) heat treated wires at $400^{\circ} \mathrm{C}$ for 20 min (NiTi400). Then, these wires were welded by TIG process, using Micromelt welder (EDG Equipment and Controls). The thermomechanical characterization of micro welded wires was performed using tests of differential scanning calorimetry (DSC), dynamic mechanical analysis (DMA), uniaxial tensile test, optical microscopy (OM), scanning electron microscopy (SEM), and Vickers microhardness. The results show the efficiency of TIG welding wires to both groups. Welded joints showed similar properties to reference wires and the fracture surface analysis showed a ductile profile.

Keywords: Shape memory alloys; NITINOL; Micro welding; Superelasticity.

1 Eng. de Materiais, Aluno de Mestrado, Unidade Acadêmica de Engenharia Mecânica (UAEM), Universidade Federal de Campina Grande (UFCG), Campina Grande, PB, Brasil.

2 Eng. Mecânico, Aluno de Doutorado, Unidade Acadêmica de Ciências e Engenharia de Materiais (UAEMa), UFCG, Campina Grande, PB, Brasil.

3 Engenheiro Mecânico, Doutor, Professor, UAEM, UFCG, Campina Grande, PB, Brasil.

4 Engenheiro Mecânico, Mestre, Professor, UAEM, UFCG, Campina Grande, PB, Brasil.

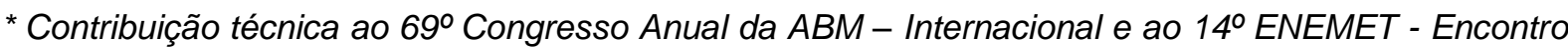
Nacional de Estudantes de Engenharia Metalúrgica, de Materiais e de Minas, 21 a 25 de julho de 2014, São Paulo, SP, Brasil.
} 


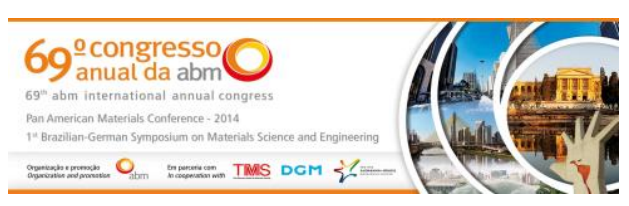

\section{INTRODUÇÃO}

As Ligas com Memória de Forma (LMF) de NiTi apresentam uma ótima combinação de propriedades funcionais, combinando os fenômenos de efeito de memória de forma (EMF) e superelasticidade (SE) que conferem a estes materiais aplicações na indústria aeroespacial, automotiva, mecatrônica e de dispositivos médicos e odontológicos [1]. Devido a razões econômicas e de processamento a fabricação de alguns tipos de atuadores de LMF se torna inviável por métodos convencionais, promovendo os processos de união de metais como uma importante maneira de produzir uma nova gama de atuadores [2].

A micro soldagem se mostra eficiente, principalmente para a união de LMF NiTi, devido ao fato de localizar o calor e minimizar a distorção térmica pela alta restrição dos tamanhos do metal de solda (MS) e da zona afetada pelo calor (ZAC), fornecendo precisão e vedação hermética, fatores necessários para aplicação desta técnica em bio implantes e micro sistemas eletromecânicos [3].

Nesse contexto, o estudo de técnicas de união por soldagem de LMF de NiTi têm despertado grande interesse nas ultimas décadas, como se observa nos seguintes trabalhos: (a) Eijk et al [4] ao estudar a soldagem por arco de plasma em fios de NiTi martensíticos, obteve valores de resistência máxima de ruptura de juntas soldadas de cerca $150 \mathrm{MPa}$; (b) Silva et al [5] obteve valores da ordem de $300 \mathrm{MPa}$ de resistência a ruptura da junta em fios de NiTi martensíticos micro soldados por descarga capacitiva; (c) Mirshekari et al [6] utilizando o processo de soldagem a laser, para a união de fios de NiTi superelásticos (austeniticos), obtiveram resultados de resistência a ruptura da junta soldada da ordem de $835 \mathrm{MPa}$; (d) Yang et al [7], ao unir chapas de NiTi com efeito de memória de forma utilizando soldagem por feixe de elétrons, obteve valores de resistência a tração da ordem de $750 \mathrm{MPa}$.

Analisando os comportamentos mecânicos de fios de NiTi micro soldados no estado austenítico, é possível notar um pequena redução da propriedade de superelasticidade nas juntas soldadas. Isto ocorre pelo fato de que os defeitos causados durante a soldagem provocam distorções que impendem os átomos voltarem as suas posições originais depois das ciclagens de carregamento e descarregamento mecânico [8]. No entanto, a medida que os fios com solda são treinados através de ciclagens repetitivas, sofrem encruamento que possibilitam o aparecimento do fenômeno de superelasticidade completa (deformação residual próximo a 0\%) [9].

Neste contexto, este trabalho teve como objetivo geral investigar o comportamento termomecânico de fios de LMF NiTi superelásticos submetidos a micro soldagem por pulsos de TIG.

\section{MATERIAIS E MÉTODOS}

Para a realização deste trabalho foram utilizados fios níquel-titânio para implante cirúrgico (ASTM F2063) com 0,9 mm de diâmetro e superfície polida, fabricados pela empresa Fort Waine Metals (EUA). Os fios foram divididos em dois grupos: (a) fios no estado como recebidos ( $\mathrm{NiTiA}$ ) e (b) fios como recebidos e tratados termicamente a $400^{\circ} \mathrm{C}$ durante 20 minutos (NiTi400). A Tabela 1 mostra a composição química e as propriedades mecânicas do fio NiTiA, segundo o fabricante.

\footnotetext{
* Contribuição técnica ao $69^{\circ}$ Congresso Anual da ABM - Internacional e ao 14ํㅡㄹ ENEMET - Encontro Nacional de Estudantes de Engenharia Metalúrgica, de Materiais e de Minas, 21 a 25 de julho de 2014, São Paulo, SP, Brasil.
} 


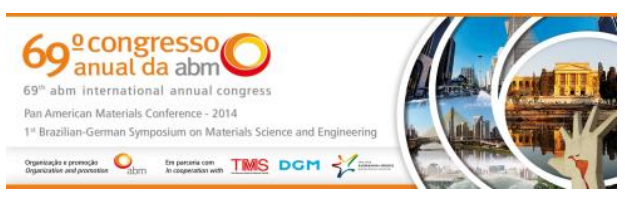

Tabela 1. Composição química e propriedades mecânicas do fio NiTiA.

\begin{tabular}{|c|c|c|c|c|c|c|c|c|}
\hline \multicolumn{9}{|c|}{ Composição Química (\% em peso) } \\
\hline $\mathrm{C}$ & $\mathrm{Cr}$ & $\mathrm{Ni}$ & $\mathrm{Ti}$ & $\mathrm{Cu}$ & Co & $\mathrm{Fe}$ & $\mathrm{H}$ & $\mathrm{O}$ \\
\hline 0,0282 & 0,00029 & 55,92 & 44,01 & 0,00037 & 0,00057 & 0,011 & $<0,005$ & 0,0277 \\
\hline \multicolumn{9}{|c|}{ Propriedades Mecânicas } \\
\hline \multicolumn{7}{|c|}{ Resistência a Tração } & \multicolumn{2}{|c|}{$1367 \mathrm{MPa}$} \\
\hline \multicolumn{7}{|c|}{ Alongamento } & \multicolumn{2}{|c|}{$15,5 \%$} \\
\hline \multicolumn{7}{|c|}{ Tensão de Escoamento* } & \multicolumn{2}{|c|}{$542 \mathrm{MPa}$} \\
\hline \multicolumn{7}{|c|}{ Dureza } & \multicolumn{2}{|c|}{$43,1 \mathrm{HRC} / 423 \mathrm{HV}$} \\
\hline
\end{tabular}

Todos os fios NiTi foram soldados utilizando o processo de solda ponto, autógena, através de pulsos de TIG (eletrodo de Tungstênio-Tório) usando a micro soldadora Micromelt, da EDG Equipamentos e Controles (Brasil), com $3 \mathrm{~kW}$ de potência máxima. Durante as soldagens foi utilizado gás argônio comercial como atmosfera de proteção da poça de fusão. Os parâmetros automáticos utilizados na soldadora Micromelt corresponderam a regulagem mínima permitida pelo equipamento: 01 de profundidade (relacionado a intensidade de corrente elétrica) e 01 de pulso (relacionado ao tempo de pulso). Foram utilizados fios $\mathrm{NiTi}$ de $40 \mathrm{~mm}$ de comprimento e um dispositivo para fixação foi confeccionado para alinhar os fios e melhorar a precisão do ponto de solda. A Figura 1 mostra os detalhes do processo de solda. Esse processo de soldagem é autógeno, sem o uso de qualquer metal de adição.

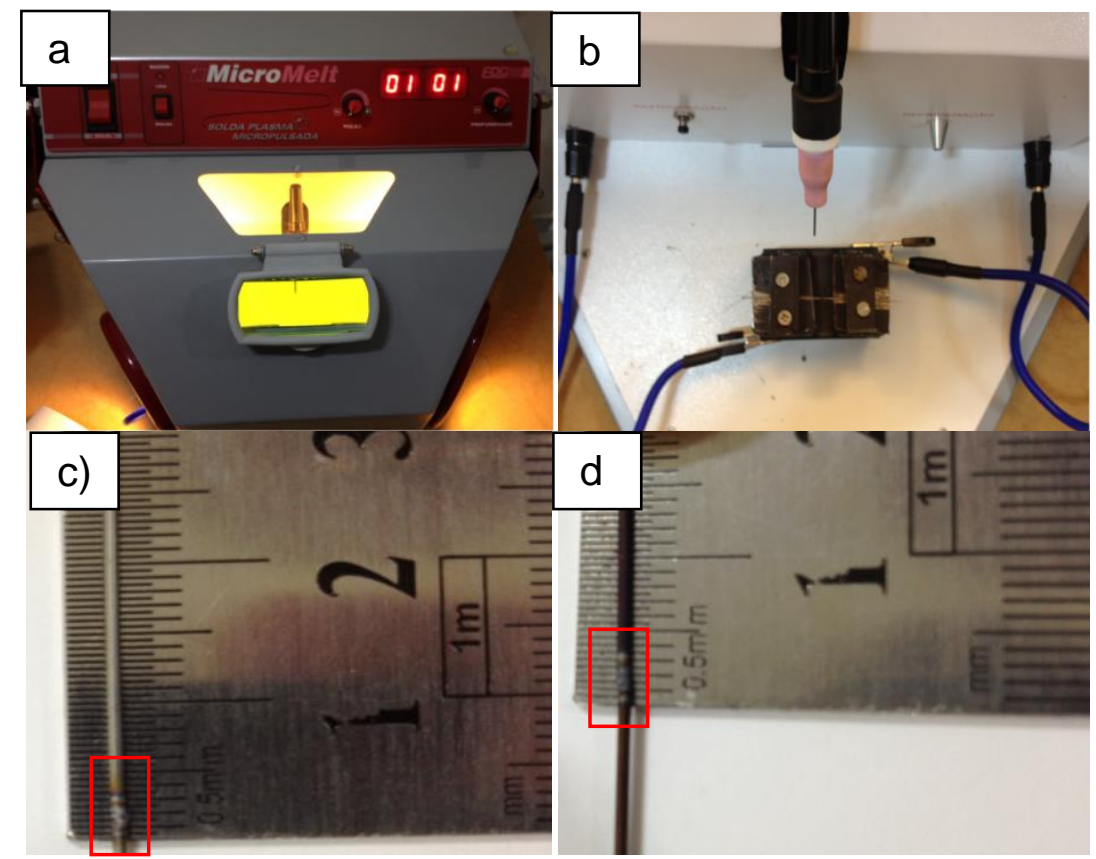

Figura 1. Esquema do processo de micro soldagem TIG: a) soldadora Micromelt; b) montagem do dispositivo de fixação dos fios para soldagem; c) solda em fios NiTiA; d) solda em fios NiTi400.

Para um melhor entendimento dos parâmetros de pulso utilizados na soldadora Micromelt, foi realizada uma medição do tempo de pulso em função da queda de tensão elétrica durante a soldagem de um fio NiTi. Para isto foi utilizado um osciloscópio digital Agilent U1602A, e a aquisição do pulso foi realizada na extremidade do eletrodo de tungstênio no momento de contato com o fio a ser

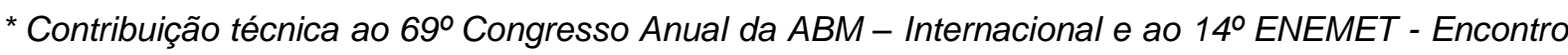
Nacional de Estudantes de Engenharia Metalúrgica, de Materiais e de Minas, 21 a 25 de julho de 2014, São Paulo, SP, Brasil.
} 


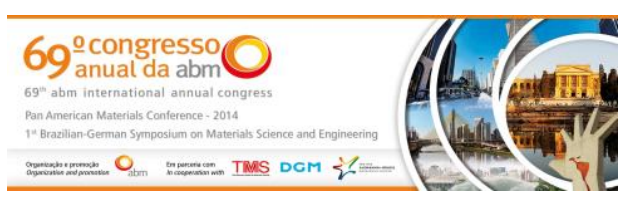

soldado. Como resultado foi obtida a curva apresentada na Figura 2, que permite verificar um tempo de pulso da ordem de $25 \mathrm{~ms}$, com uma queda de tensão atingindo valores próximos de $5 \mathrm{mV}$.

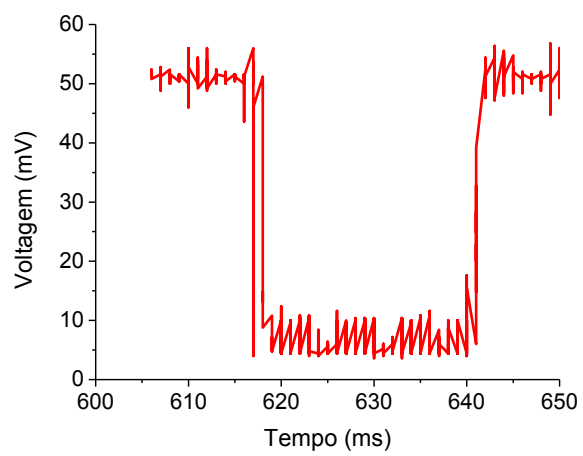

Figura 2. Aquisição do tempo de pulso de soldagem por um osciloscópio digital.

As transformações de fases dos fios NiTi íntegros e micro soldados foram analisadas a partir de ensaios de Calorimetria Diferencial de Varredura (DSC) utilizando um equipamento da TA Instruments, modelo Q20, em que as amostras de fio com $5 \mathrm{~mm}$ de comprimento foram submetidas a varredura na faixa de temperatura de $-60^{\circ} \mathrm{C}$ até $100^{\circ} \mathrm{C}$ com uma taxa de aquecimento e resfriamento de $5^{\circ} \mathrm{C} / \mathrm{min}$.

A caracterização da resistência mecânica dos fios de $\mathrm{NiTi}$ soldados e isentos de solda, foi realizada através do ensaio tração uniaxial, à temperatura ambiente (aproximadamente $24^{\circ} \mathrm{C}$ ), utilizando-se uma máquina universal de ensaios eletromecânica, INSTRON, modelo 5582. Foram realizados ensaios de ruptura e ciclagem mecânica. Para a ciclagem foi gerado um método para controle de deslocamento durante o carregamento, limitando em $4 \%$ a deformação relativa ao comprimento útil do fio, com velocidade de $0,5 \mathrm{~mm} / \mathrm{min}$. Em seguida foi realizado 0 descarregamento controlado também a $0,5 \mathrm{~mm} / \mathrm{min}$ até atingir tensões residuais da ordem de $10 \mathrm{MPa}$.

Para melhor compreensão da influência da solda sobre as características termomecânicas dos fios $\mathrm{NiTi}$, foram realizadas análises dinâmico-mecânica dos fios soldados e íntegros utilizando um equipamento de DMA (Dynamic Mechanical Analysis), modelo Q800, da TA Instruments. O experimento em DMA consiste na aplicação de uma força oscilatória (modo de flexão simples) em um intervalo de temperatura determinado $\left(24^{\circ} \mathrm{C}-100^{\circ} \mathrm{C}\right)$ obtendo como resposta variações no módulo de elasticidade. Os parâmetros utilizados para a realização dos ensaios dinâmicos foram: frequência de $1,0 \mathrm{~Hz}$, taxa de aquecimento de $2^{\circ} \mathrm{C} / \mathrm{min}$ e amplitude de oscilação de $5 \mu \mathrm{m}$. Portanto, os ensaios realizados corresponderam a uma rampa de aquecimento partindo da temperatura ambiente, com frequência $e$ amplitude fixada.

Os ensaios de microindentação foram realizados utilizando o microdurômetro FM700 da Future Tech, com um indentador Vickers, aplicando uma carga de $50 \mathrm{~g}$ durante 15 segundos.

Para a análise metalográfica, os fios foram embutidos, lixados (600-1200), polidos (sílica coloidal) e atacados $\left(20 \% \mathrm{HF}-30 \% \mathrm{HNO}_{3}-50 \% \mathrm{H}_{2} \mathrm{O}\right)$, para em seguida realizar a análise de microscopia óptica (Microscópio Olympus SC30) e microscopia eletrônica de varredura (Tescan, modelo Vega3 XM). Esta última foi também utilizada para análises de superfícies de ruptura dos fios NiTi.

\footnotetext{
* Contribuição técnica ao $69^{\circ}$ Congresso Anual da ABM - Internacional e ao 14ํㅡㄹ ENEMET - Encontro Nacional de Estudantes de Engenharia Metalúrgica, de Materiais e de Minas, 21 a 25 de julho de 2014, São Paulo, SP, Brasil.
} 


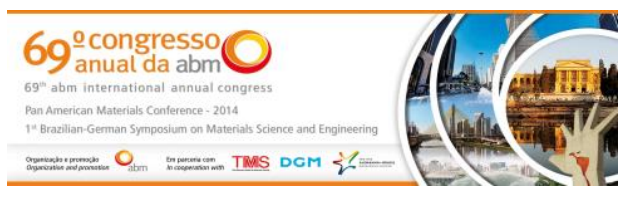

\section{RESULTADOS E DISCUSSÃO}

\subsection{Ensaios de DSC}

O ensaio de DSC consiste em um importante método de medição das temperaturas de transformações de fases em LMF, possibilitando o melhor entendimento das faixas de temperatura em que ocorrem os fenômenos de superelasticidade e efeito de memória de forma, e permitindo direcionar cada tipo de material para suas respectivas aplicações. A Figura 3 mostra, em (a), curvas de DSC de fios NiTiA comparando fios de referência e fios com solda, enquanto em (b) são apresentadas curvas de DSC de fios de NiTi400, comparando fios de referência e fio com solda. Analisando as Figuras 3 (a) e (b) nota-se que, na temperatura ambiente $\left(25^{\circ} \mathrm{C}\right)$, os fios sem solda NiTiA encontram-se na fase austenita, enquanto os fios NiTi400 estão em um estado misto (martensita e austenita). Adicionalmente, nos fios com solda ocorre um deslocamento dos picos característicos de transformação, correspondendo a uma diminuição das temperaturas de transformação de fase. Tomando por base os picos da transformação reversa no aquecimento (martensita para austenita), esta diminuição das temperaturas de transformação após a micro soldagem TIG é da ordem de $30^{\circ} \mathrm{C}$ para o fio NiTiA e de $55^{\circ} \mathrm{C}$. O comportamento de deslocamento das temperaturas de transformação de fase pode estar associado a: (i) remoção do processamento a frio do metal de base [3] e (ii) presença de defeitos induzidos pelo calor na microestrutura do metal de solda, como tensões residuais e crescimento de grão [10].

(a)

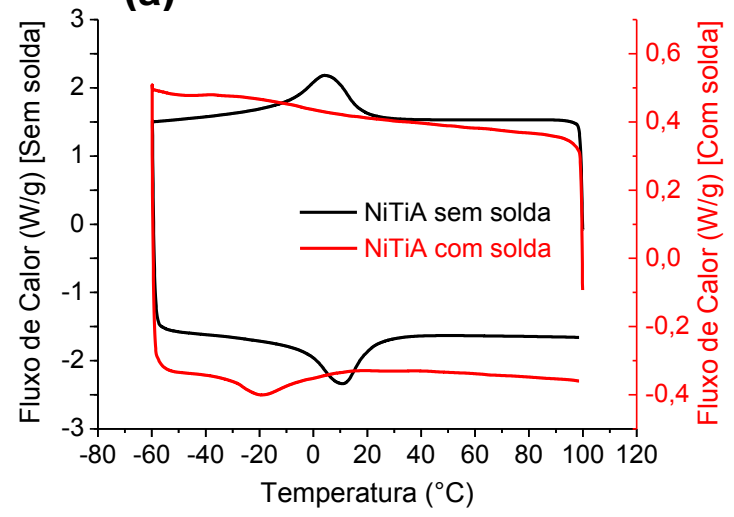

(b)

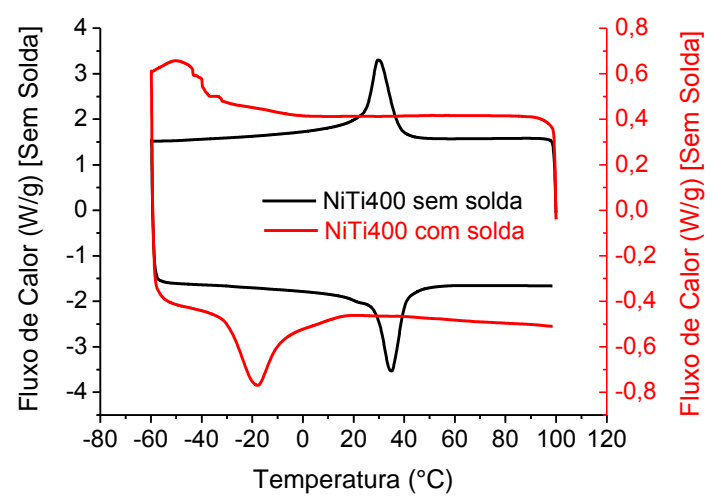

Figura 3. Curvas de DSC para (a) fios superelásticos de referência e fios superelásticos com solda (NiTiA); (b) fios tratados termicamente de referência e com solda (NiTi400).

\subsection{Ensaios de DMA}

Os ensaios de DMA são importantes para determinar propriedades termomecânicas em LMF. Neste estudo estes ensaios foram conduzidos para avaliar possíveis mudanças de rigidez (módulo de elasticidade) em função da temperatura dos fios NiTi. A Figura 4(a) permite comparar o comportamento do módulo de elasticidade de fios NiTiA de referência com fios NiTiA com solda. É possível verificar que ambos os fios apresentam o mesmo tipo de comportamento qualitativo, correspondente a um pequeno aumento quase linear do módulo de elasticidade em função da temperatura. No entanto, os valores de módulo de elasticidade dos fios com solda diminuem em aproximadamente 15 GPa. Já a Figura 4(b) mostra os

\footnotetext{
* Contribuição técnica ao 69 Congresso Anual da ABM - Internacional e ao 14ํㅡㄹ ENEMET - Encontro Nacional de Estudantes de Engenharia Metalúrgica, de Materiais e de Minas, 21 a 25 de julho de 2014, São Paulo, SP, Brasil.
} 


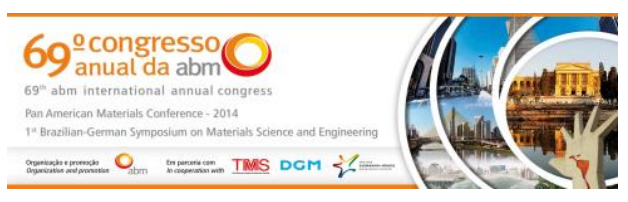

comportamentos de fios NiTi400 de referência e fios NiTi400 com solda. Nota-se que neste caso também são observados perfis de comportamento semelhantes, no entanto ocorre uma diminuição situada entre 2,5 GPa e $10 \mathrm{GPa}$ nos valores de módulo de elasticidade para os fios NiTi400 com solda, na faixa de temperatura estudada. É possível sugerir então que a solda não afeta os perfis qualitativos de comportamento termomecânico para ambos os fios. Considerando que a partir de $30^{\circ} \mathrm{C}$ os resultados de DSC (Figura 3 ) já indicavam que os fios estavam em estado austenítico, o aumento limitado do módulo de elasticidade em função da temperatura para o fio no estado como recebido (NiTiA) é um resultado esperado. Além disso, os valores de módulo de elasticidade, situados em ambos os casos entre $40 \mathrm{GPa}$ e 75 GPa, são compatíveis com aqueles apresentados na literatura para LMF NiTi $[1,11]$.
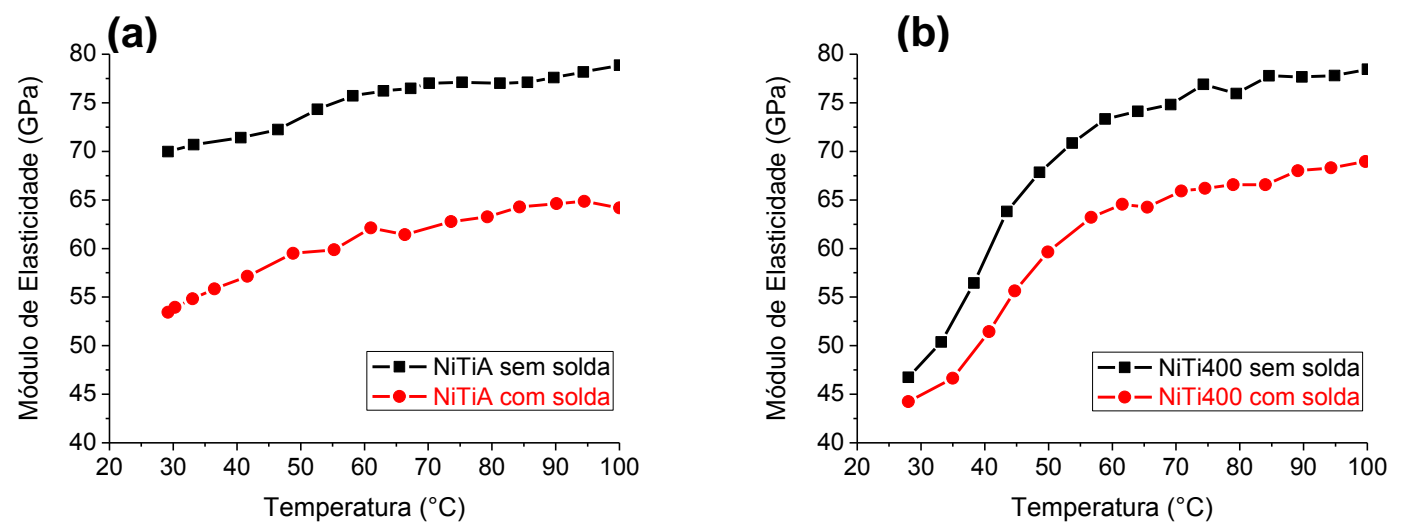

Figura 4. Variação de módulo de elasticidade em função da temperatura para (a) fio NiTi A de referência e com solda; (b) fio NiTi400 de referência e com solda.

\subsection{Análise Microestrutural}

Ao observar as imagens de microscopia ótica da Figura 5 é possível notar que ambos os fios (NiTiA e NiTi400) apresentam morfologias semelhantes, consistindo em uma visível linha de solda que define a região em que houve a união autógena de topo entre os fios. Nas proximidades dessa região existem continuidades de grãos colunares oriundos da interface entre o metal fundido na soldagem e a zona afetada pelo calor (ZAC). Essa região é seguida pela ZAC e o metal de base (não fundido durante a soldagem e não afetado pelo calor), ambas com grãos equiaxiais. As Figuras 6 (a) e (b) mostram, por meio de uma maior ampliação em MEV, a interface entre a ZAC de grãos equiaxiais grosseiros e o metal fundido na soldagem constituído por grãos colunares (a) e a linha de solda (b) para o fio NiTiA. Observando as Figuras 6 (c) e (d) é possível observar a semelhança morfológica dos grãos do fio NiTi400 quando comparados ao fio NiTiA.

\footnotetext{
* Contribuição técnica ao $69^{\circ}$ Congresso Anual da ABM - Internacional e ao 14ํㅡㄹ ENEMET - Encontro Nacional de Estudantes de Engenharia Metalúrgica, de Materiais e de Minas, 21 a 25 de julho de 2014, São Paulo, SP, Brasil.
} 

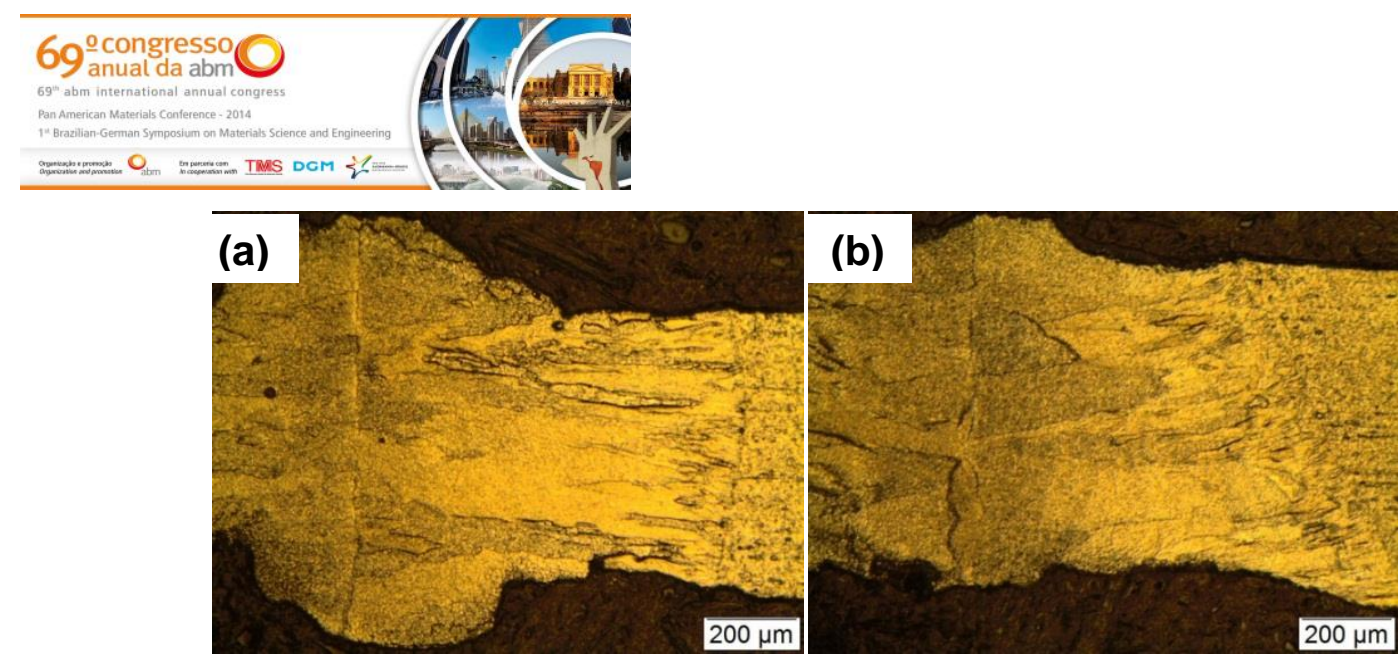

Figura 5. Microestrutura obtida por microscopia ótica para (a) fio NiTiA com solda e (b) fio NiTi400 com solda.

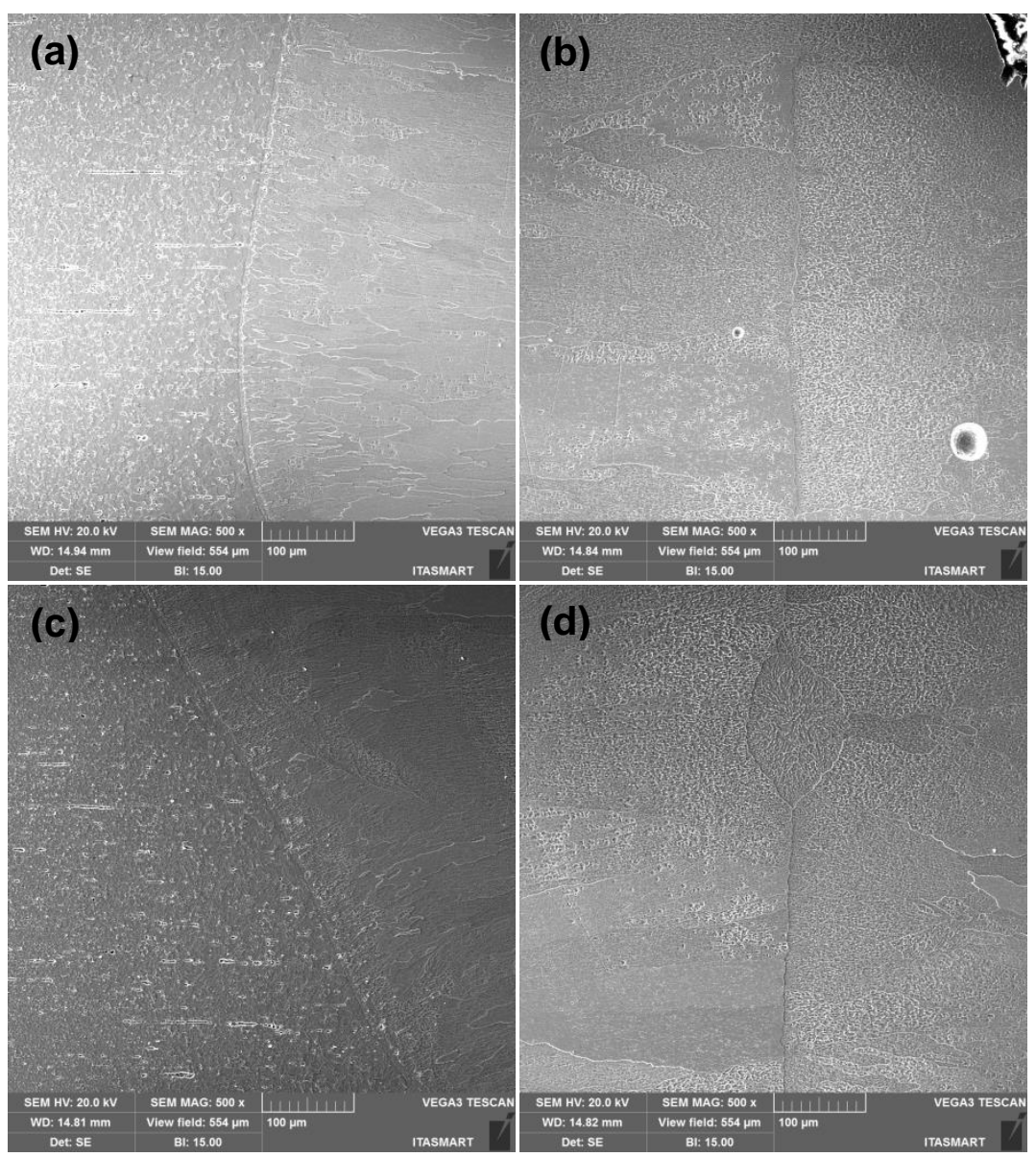

Figura 6. Microestrutura obtida por microscopia eletrônica de varredura para (a) interface entre metal fundido na soldagem e ZAC para fio NiTiA, (b) linha de solda para fio NiTiA, (c) interface entre metal fundido na soldagem e ZAC para fio NiTi400, (d) linha de solda para fio NiTi400.

\subsection{Análise de Dureza}

A Figura 7 mostra a distribuição de dureza para os fios NiTiA e NiTi400. Os valores de dureza para ambos os fios no metal fundido na soldagem (região da solda) e no metal de base (região não afetada pela solda) foram de $250-280 \mathrm{HV}$ e $425-480 \mathrm{HV}$, respectivamente. Especificamente, o valor médio de aproximadamente $425 \mathrm{HV}$ para o metal de base do fio $\mathrm{NiTi}$ como recebido (NiTiA) está em acordo com aquele informado pelo fabricante (Tabela 1). Ao observar o comportamento de dureza na zona afetada pelo calor (ZAC) constata-se que a dureza inicialmente é baixa na região da interface com o metal fundido na soldagem e em seguida ocorre um

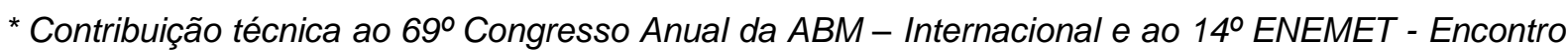
Nacional de Estudantes de Engenharia Metalúrgica, de Materiais e de Minas, 21 a 25 de julho de 2014, São Paulo, SP, Brasil. 


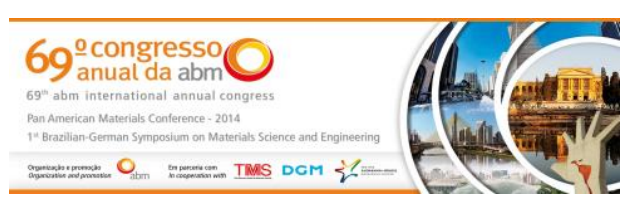

aumento em direção ao metal de base. Essa transição nos valores de dureza na ZAC ocorre devido ao fenômeno de crescimento de grão, em que uma estrutura de grão fino é observada próximo ao metal de base, enquanto que grãos próximos ao metal fundido na soldagem são grosseiros. Esse comportamento ocorre devido a alta velocidade de resfriamento na região próxima ao metal de base e a baixa velocidade de resfriamento na região próxima ao metal fundido na soldagem [6]. Observando a Figura 7(b) é possível ainda perceber regiões com picos de dureza elevados ( $350 \mathrm{HV})$ no metal fundido na soldagem, indicando que, possivelmente, o tratamento térmico realizado na amostra a $400^{\circ} \mathrm{C}$ proporcionou o aparecimento de precipitados.
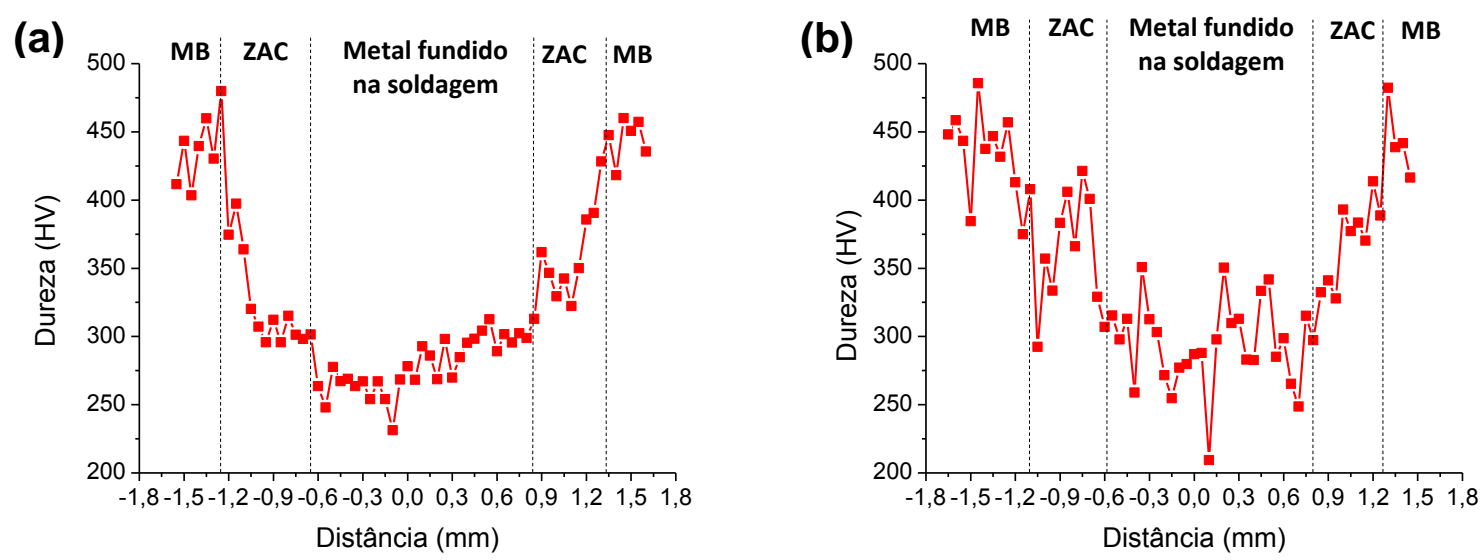

Figura 7. Distribuição de dureza para os fios soldados (a) NiTiA e (b) NiTi400.

\subsection{Caracterização Mecânica}

A micro soldagem autógena por pulsos de TIG possibilitou a união tanto dos fios como recebidos ( $\mathrm{NiTiA}$ ) quanto dos fios tratados termicamente (NiTi400), sendo necessário somente um ponto de solda para obter juntas soldadas aceitáveis. Com o objetivo de verificar a eficiência mecânica das juntas soldadas foram realizados ensaios de tração uniaxial conduzidos até a ruptura, permitindo comparar a resistência mecânica dos fios de referência com os fios soldados. As Figuras 8 (a) e (b) mostram curvas de tensão-deformação para fios NiTiA e NiTi400, respectivamente. Analisando a Figura 8(a) nota-se que a ruptura do fio NiTiA com solda ocorre em cerca de $60 \%$ da deformação do fio de referência, atingindo valores de tensão da ordem de 550MPa. Este valor de patamar de tensão é compatível com a tensão de escoamento informada pelo fabricante (Tabela 1). Já o fio NiTi400 (Figura $8 b$ ) se rompe com cerca de $45 \%$ da deformação do fio de referência, atingindo valores de tensão da ordem de 500MPa. A ruptura prematura dos fios soldados, ao final do patamar de tensão constante correspondente a formação de martensita induzida, provavelmente é consequência das mudanças a níveis microestruturais, como crescimento de grão e aparecimento de defeitos ocasionados pelo processo de soldagem.

Para verificar as propriedades de superelasticidade, foram realizadas comparações entre os fios $\mathrm{NiTi}$ de referência e os fios NiTi soldados, por meio de ciclagens com taxas de carregamento e descarregamento controladas. As Figuras 9 (a) e (b) mostram ciclos de tensão-deformação com deformações máximas de $4 \%$ para os fios NiTiA e NiTi400, respectivamente.

\footnotetext{
* Contribuição técnica ao 69ำ Congresso Anual da ABM - Internacional e ao 14ํㅡㄹ ENEMET - Encontro Nacional de Estudantes de Engenharia Metalúrgica, de Materiais e de Minas, 21 a 25 de julho de 2014, São Paulo, SP, Brasil.
} 

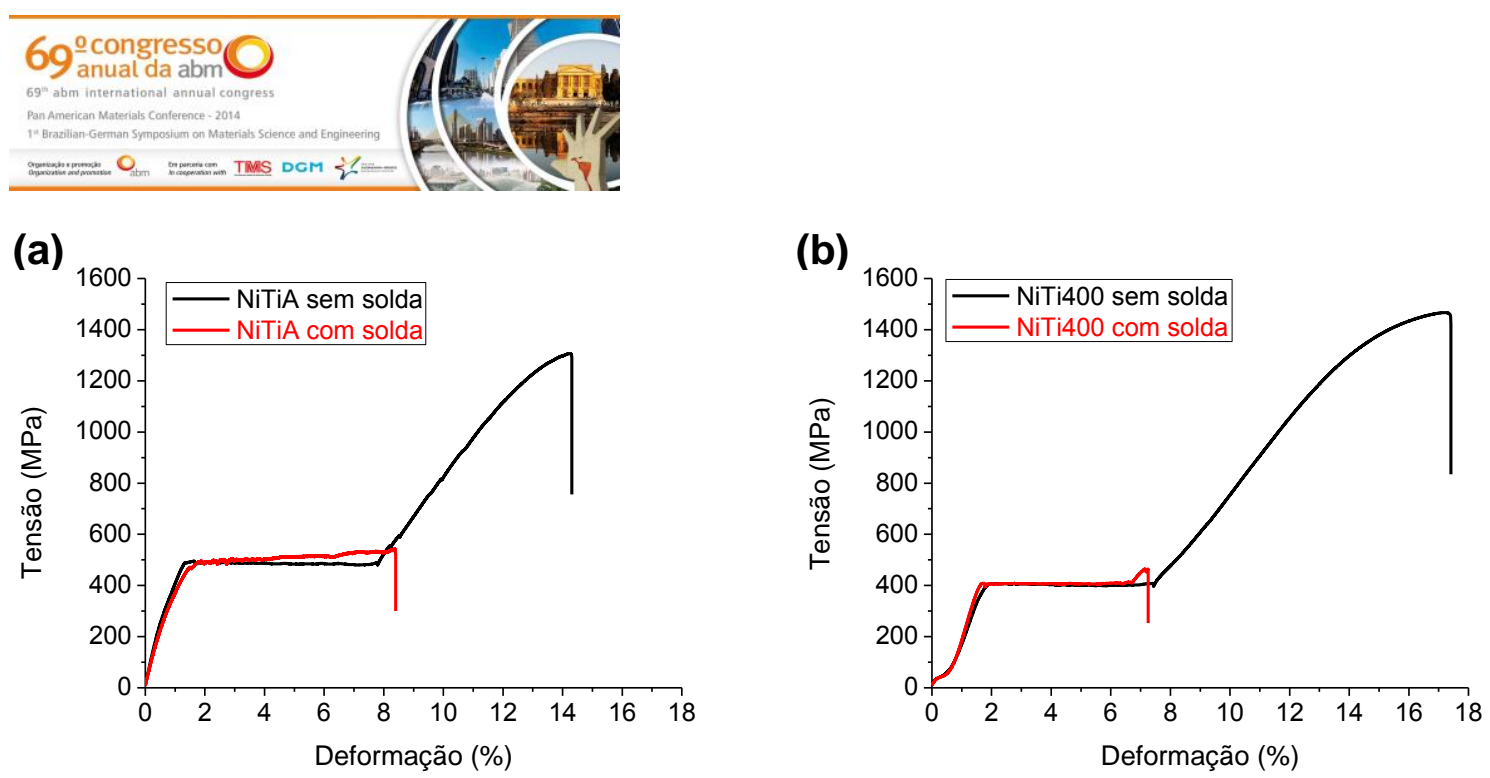

Figura 8. Ensaios de tração realizados até a ruptura para: (a) fios NiTiA de referência e fios NiTiA com solda; (b) fios NiTi400 de referência e fios NiTi400 com solda.

Ao analisar a Figura 9 (a) é possível afirmar que os fios NiTiA com solda apresentam pouca diferença de comportamento ao longo do ciclo quando comparados aos fios NiTiA de referência. Este comportamento se deve ao fato de que ao soldar estes materiais ocorre um rearranjo local a nível microestrutural, o qual torna o fio NiTi susceptível de estabilização de suas propriedades de superelasticidade na região soldada. A Figura 9 (b) permite uma comparação entre os fios NiTi400 de referência e fios NiTi400 com solda. Nesse caso, observa-se uma primeira região limitada a 1\% de deformação que corresponde à formação da martensita do tipo fase $\mathrm{R}$ induzida por tensão. Esse comportamento de aparecimento da fase R é mais um indicativo da formação de precipitados ricos em Ni após o tratamento térmico [1]. Após o descarregamento, verifica-se que existe uma deformação residual da ordem de $0,8 \%$, em ambos os fios, que pode ser recuperada por efeito de memória de forma após aquecimento. Esse comportamento é típico de fios superelásticos com resquícios de presença de martensita (fase $R$, nesse caso).

(a)

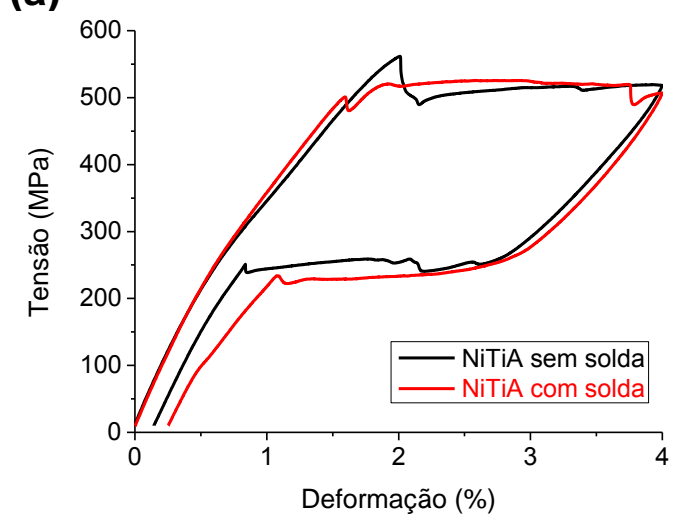

(b)

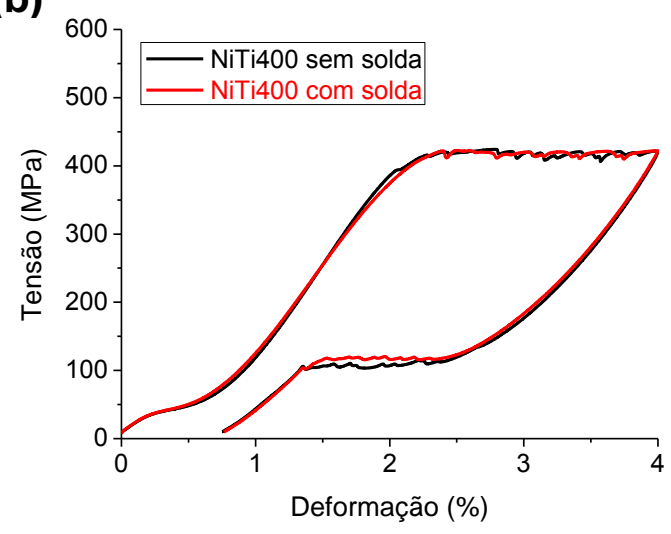

Figura 9. Ciclagem mecânica até $4 \%$ de deformação a temperatura ambiente para (a) fio NiTiA de referência e fio NiTiA com solda, (b) fio NiTi400 de referência e fios NiTi400 com solda.

\subsection{Análise do Perfil de Fratura}

As Figuras 10 (a) e (b) mostram imagens em microscopia ótica referentes aos aspectos macroscópicos da fratura para os fios NiTiA e NiTi400, respectivamente. Ambos os fios apresentaram fratura na região de interface entre o metal fundido na soldagem e a ZAC. Isto ocorre provavelmente devido a alta velocidade de

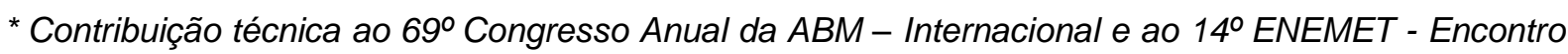
Nacional de Estudantes de Engenharia Metalúrgica, de Materiais e de Minas, 21 a 25 de julho de 2014, São Paulo, SP, Brasil. 
ropagação da trinca em grãos colunares que crescem da ZAC em direção a linha de solda.
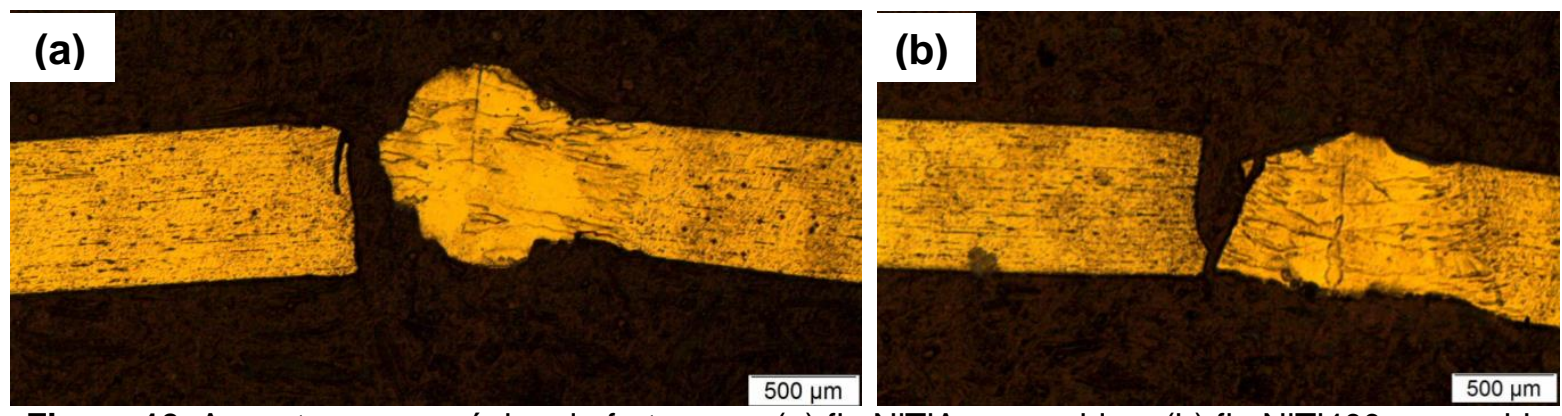

Figura 10. Aspecto macroscópico da fratura em (a) fio NiTiA com solda e (b) fio NiTi400 com solda.

As superfícies de fratura da Figura 11 revelam que tanto os fios $\operatorname{NiTiA}$ (a) e (b) quanto os fios NiTi400 (c) e (d) apresentaram regiões de fratura dúctil, caracterizadas pelo aparecimento de microcavidades (dimples). As superfícies também revelaram regiões de fratura frágil caracterizadas pela presença de superfícies de clivagem. A análise macroscópica e as superfícies de fratura confirmaram os resultados de ensaios mecânicos de tração (Figura 8), pois ambos os fios apresentaram deformações de cerca de $8 \%$ (caráter dúctil), no entanto estes fios não conseguem suportar maiores deformações devido a morfologia colunar do metal fundido na soldagem, em virtude da rápida velocidade de propagação de trincas.
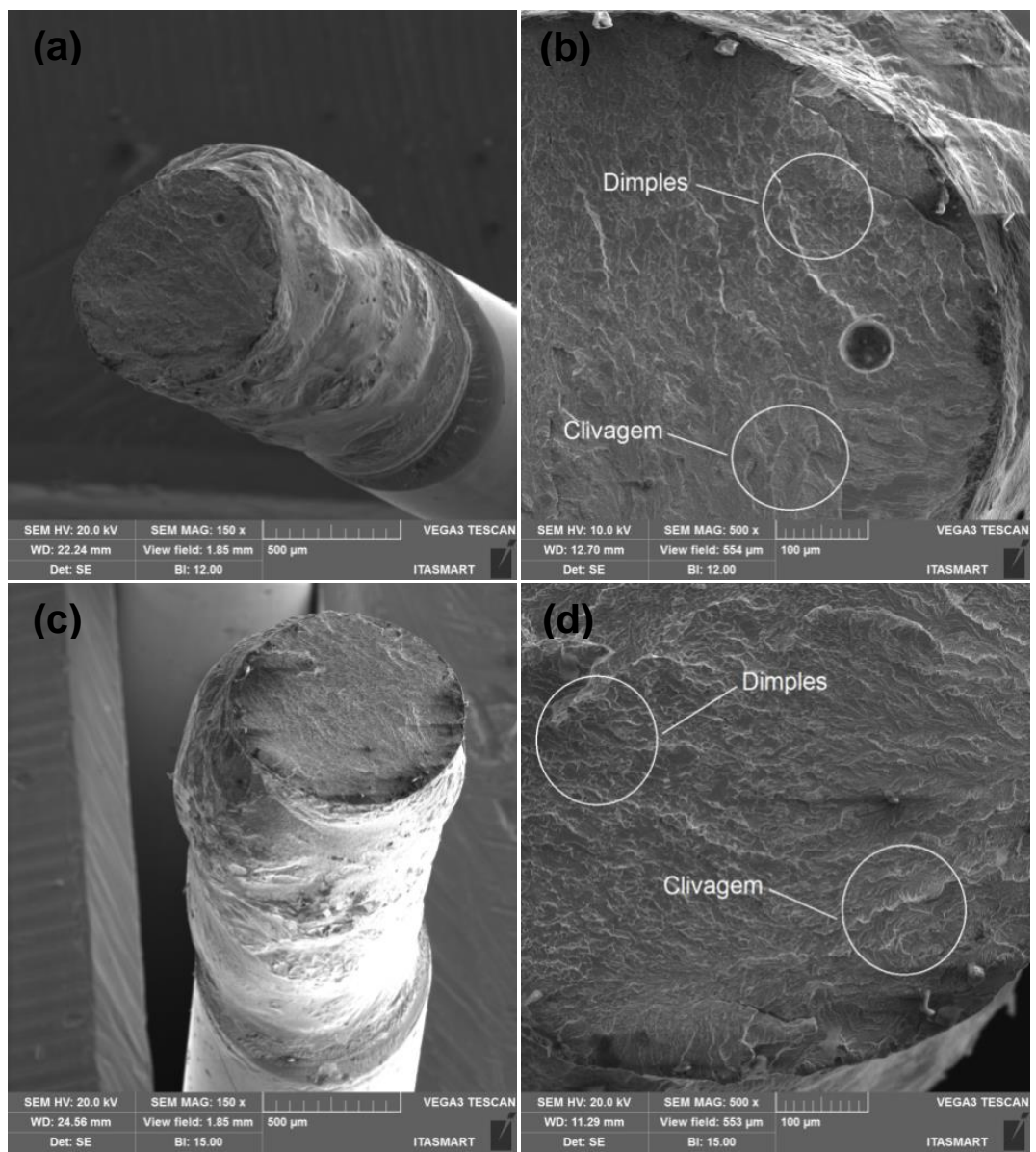

Figura 11. Superfícies de fratura para: (a) e (b) fio NiTiA com solda; (c) e (d) fio NiTi400 com solda.

\footnotetext{
* Contribuição técnica ao 69 Congresso Anual da ABM - Internacional e ao 14ํㅡㄹ ENEMET - Encontro Nacional de Estudantes de Engenharia Metalúrgica, de Materiais e de Minas, 21 a 25 de julho de 2014, São Paulo, SP, Brasil.
} 


\section{CONCLUSÃO}

De acordo com os resultados obtidos neste estudo experimental de avaliação dos comportamentos termomecânicos de fios $\mathrm{NiTi}$ superelásticos micro soldados por pulsos de TIG, é possível concluir que:

- O processo de soldagem por pulsos de TIG se mostrou eficiente na obtenção de juntas soldadas com boas propriedades superelásticas;

- O processo de soldagem pode promover mudanças a nível microestrutural que resultam em mudanças (diminuição) nas temperaturas de transformação de fase dos fios de LMF NiTi;

- O metal fundido na soldagem apresenta menores valores de dureza devido a presença de grãos colunares, enquanto que os maiores valores de dureza são encontrados no metal de base original devido a presença de finos grãos equiaxiais;

- As análises dos fios NiTi com solda mostraram que a fratura tende a ocorrer na região de interface entre o metal fundido na soldagem e a ZAC. A superfície de fratura nos fios com solda apresentaram superfícies com interfaces de fratura dúctil entre superfícies de clivagens (fratura frágil).

\section{Agradecimentos}

Os autores agradecem ao grupo ITASMART, chefiado pelo Prof. Jorge Otubo, pela disponibilização do microscópio eletrônico de varredura para as análises microestruturais e ao CNPq pelo financiamento dos projetos: INCT de Estruturas Inteligentes em Engenharia (Processo $n^{\circ}$ 574001/2008-5), Casadinho UFCG-UFRJITA (Processo no 552199/2011-7), Universal 14/2012 (Processo n 474524/2012-4), CT-Aeroespacial 22/2013 (Processo $n^{\circ}$ 402082/2013-3) e PQ 2 (Processo $n^{\circ}$ 302320/2011-3).

\section{REFERÊNCIAS}

1 Otsuka K, Wayman Cm. Shape Memory Materials. Cambridge: Cambridge University Press, London; 1998.

2 Falvo A, Furgiuele FM, Maletta C. 2008. Funcional behaviour of a NiTi-welded joint: Two-way shape memory effect. Materials Science and Engineering A, 2008; 481-482 : 647-650.

3 Chan $\mathrm{Cw}$, Chan Shj, Man Hc, Ji P. Constitutive model for localized Lüders-like stressinduced martensitic transformation and super-elastic behaviors of laser-welded NiTi wires. Computational Materials Science, 2012; 63: 197-206.

4 Eijk Cv, Fostervoll V, Sallom Zk, Akselsen Om. Plasma Welding of $\mathrm{NiTi}$ to NiTi, Stainless Steel and Hastelloy C276. ASM Materials Solutions 2003 Conference. Pennsylvania, USA. 2003.

5 Silva Jgv, Grassi E, Araújo Cj. Comportamento Termomecânico de fios NiTiNOL Microsoldados por Descarga Capacitiva: Um Estudo Experimental. VI Congresso Nacional de Engenharia Mecânica - CONEM 2010. Paraíba, Brasil. 2010.

6 Mirshekari Gr, Saatchi A, Kermanpur A, Sadrnezhaad Sk. Laser welding of NiTi shape memory alloy: Comparision of the similar and dissimalar joints to AISI 304 stainless steel. Optics \& Laser Technology, 2013; 54: 151-158.

7 Yang D, Jiang Hc, Zhao Mj, Rong Lj. Microstruture and mechanical behaviors of electron beam welded NiTi shape memory alloys. Materials and Design, 2014;21-25.

8 Tuissi A, Besseghini S, Ranucci T, Squatrito F, Pozzi M. Effect of Nd-YAG laser welding

* Contribuição técnica ao $69^{\circ}$ Congresso Anual da ABM - Internacional e ao 14ํㅡㄹ ENEMET - Encontro Nacional de Estudantes de Engenharia Metalúrgica, de Materiais e de Minas, 21 a 25 de julho de 2014, São Paulo, SP, Brasil. 
on the functional properties of the Ni-49,6at.\%Ti. Materials Science and Engineering A, 1999 ; 273-275: 813-817.

9 Amorim Fa, Sousa Tts, Rodrigues Lfa, Araújo Cj, Maciel Tm. Evaluation of the thermomechanical behavior of NITINOL wires micro welded by plasma arc pulses. 22nd International Congress of Mechanical Engineering - COBEM 2013. Ribeirão Preto, Brasil. 2013

10 Chan $\mathrm{Cw}$, Man Hc, Cheng Ft. Fatigue behavior of laser-welded NiTi wires in small strain cyclic bending. Materials Science \& Engineering A, 2013; 559: 407-415.

11 Lagoudas DC. Shape Memory Alloys: Modeling and Engineering Applications.Texas: Springer. 2008.

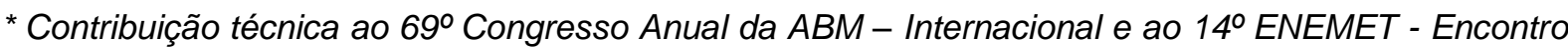
Nacional de Estudantes de Engenharia Metalúrgica, de Materiais e de Minas, 21 a 25 de julho de 2014, São Paulo, SP, Brasil. 